\title{
TRÍADAS PUTUMAYENSES: RELLACIONES PATRÓN-CLIENTE en la economía de la cocaína
}

\author{
OSCAR JANSSON \\ UNIVERSIDAD DE UPPSALA \\ Oscar.Jansson@antro.uu.se
}

\begin{abstract}
Resumen
[ STE TEXTO ANALIZA LAS RELACiONES DE PRODUCCión DE COCA EN EL BAJO Putumayo [ (Colombia) como relaciones de patrón-cliente. El artículo sostiene que el intercambio de muestras tangibles de buena voluntad entre los intermediarios, por muestras intangibles de buena voluntad de los productores de materia prima, enmascara la subordinación del productor de materia prima en relaciones verticales de dominación y explotación. Mientras el productor de materia prima está en el nivel más bajo en esas relaciones, el intermediario representa sólo un corredor en una estructura triádica cuya cabeza está representada por el productor de cocaína. El análisis demuestra, sin embargo, que la forma particular de subordinación de los productores de materia prima, en cuanto a su sometimiento a la explotación, la violencia y la proyección de fuerza por grupos armados, descansa en gran medida en la capacidad que tenga el intermediario de negociar con el productor de cocaína.
\end{abstract}

PALABRAS Clave: relaciones patrón-cliente, producción de cocaina, Putumayo.

\section{Abstract}

This PAPER ANALYZES COCAINE'S RELATIONS OF PRODUCTION IN SOUTHERN PUtUMAYO through the lens of patron-client relations. I argue that the exchange of intangible for tangible signs of goodwill between primary producers and middlemen masks vertical relations of dominance and submission. While the primary producer is situated at the lowest level in these relations, the middleman is a mere broker in a triadic structure whose head is represented by the cocaine producer. Nevertheless, as I demonstrate in the article, primary producers' particular form of submission regarding their subjection to the exploitation, violence, and power exercised by armed groups, is conditioned by the capacity of the intermediary to negotiate with the cocaine producer.

KEY WORDS: Patron-client relations, cocaine production, Putumayo.

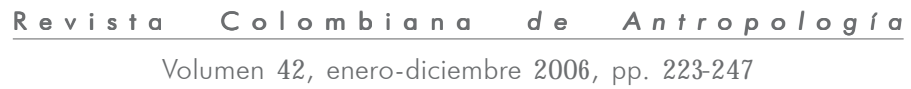




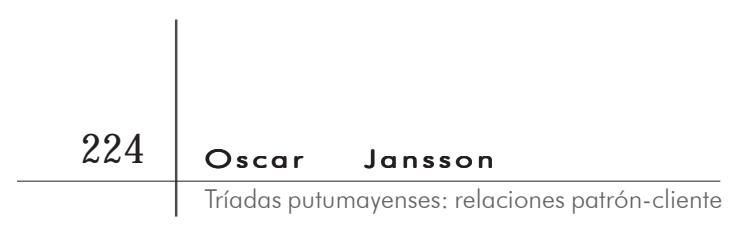

\section{INTRODUCCIÓN}

STE ARTÍCULO ANALIZA LAS RELACIONES DE PRODUCCIÓN DE COCAÍNA EN - el bajo Putumayo (Colombia) como relaciones patrón-cliente, y L es uno de los resultados de tres periodos de trabajo de campo en la región, realizadados entre 2002 y 2006 . Parte de un proyecto de investigación sobre economía política e ideología de la producción de cocaína en el sur de Colombia, cuyo resultado final se publicará próximamente en mi tesis de doctorado*. En vista de la naturaleza delicada de la información, omito las fechas, los lugares de las entrevistas y los nombres verdaderos de

* El trabajo de tesis y el artículo han sido posibles gracias a financiación otorgada por el Departamento de Cooperación para Investigación de la Agencia Sueca de Cooperación Internacional para el Desarrollo (ASDI) y el Foro Colombia de la Universidad de Uppsala. las personas mencionadas, con el fin de resguardar la integridad de mis informantes.

Comparada con otras clases de coaliciones entre actores de grupos sociales superiores e inferiores, la relación patrón-cliente en etnografía e historiografía en comunidades campesinas y dentro de las elites políticas y económicas, se caracteriza por un contenido más amplio que la simple transacción económica: es una coalición de entrelazamiento múltiple, si se utiliza este término metafórico de Wolf (1966a), equiparable con una cuerda consistente en muchas tiras de fibra entrelazadas (Ibid.: 81, 84). La simple transacción económica entre las partes constituyentes está acompañada por un lazo de amistad, que en ocasiones parece una relación de parentesco y otras veces de vecindad, que a la vez fortalece y se ve fortalecida por la relación económica, de la misma forma en que diversas tiras entrelazadas se apoyan entre sí. La relación de amistad supone que las partes constituyentes den muestras de buena voluntad. En el caso del patrón, en su cualidad de actor superior en la coalición, estas muestras son tangibles y consisten en préstamos y créditos, mientras el cliente, en su posición económicamente inferior, se ve obligado a proporcionar muestras intangibles, sobre todo declaraciones continuas de lealtad y contribuir al mantenimiento de la buena fama de su patrón (Ibid.: 87).

La importancia de los conceptos de patrón y cliente para el análisis de escenarios políticos y económicos en las regiones rurales de Colombia ha sido sugerida repetidas veces. Schmidt 


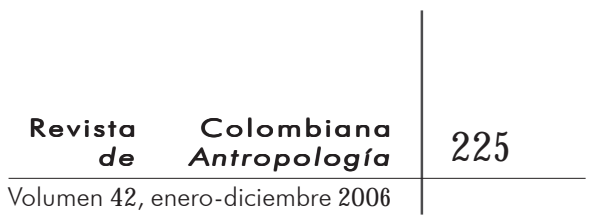

(1974: 105) vio en la relación patrón-cliente una estructura analítica capaz de enriquecer la pobreza conceptual del estudio de la Violencia en Colombia, por su comprensión del entrelazamiento entre relaciones de dependencia y lealtad. Le Grand (1977: 15), por su parte, observó cómo la reciprocidad personalizada y afectiva entre actores con recursos desiguales podía servir para exponer la forma y el contenido de enlaces particulares entre ámbitos locales y nacionales en el país. En cuanto a la producción de cocaína y su capacidad de enriquecer y sostener una variedad de actores, y también de integrarlos socialmente, los conceptos de patrón y cliente parecen más adecuados todavía.

Mientras cada eslabón en la cadena de producción constituye en sí mismo un subsistema con dinámicas particulares, cuyos protagonistas carecen muchas veces del conocimiento íntimo de las actividades propias de los niveles superiores o inferiores, existe un oficio con una visión general relativa de las relaciones sociales de producción: este oficio es el del intermediario, que consigue la base de los cultivadores para pasarla al productor de cocaína, es decir, al propietario del laboratorio donde se cristaliza la base, el llamado patrón duro. El intermediario, quien vive de la comisión que constituye la diferencia entre los precios en las transacciones con sus campesinos y su patrón duro, puede ser un comisionista, es decir, un individuo que trabaja como comerciante de base, o la guerrilla. Empezaré con el primero.

\section{EL DOBLE INTERCAMBIO ENTRE EL COMISIONISTA Y EL CAMPESINO}

\footnotetext{
N SU CUALIDAD DE NEXO SOCIAL Y ECONÓMICO, EL COMISIONISTA - representa no sólo un informante importante para el antropólogo que busca entender las relaciones de producción, sino, también, un punto de partida para la representación del conjunto de intercambios sociales y económicos que al final se ven materializados en la cocaína refinada. El comisionista recibe al campesino en su casa, que suele estar ubicada en las afueras de los cascos urbanos. Para determinar el precio de la mercancía mide su peso y hace una prueba de su calidad, conocida entre los campesinos y los comisionistas como el ensayo. Para el ensayo se usa normalmente un gramo de la pasta, que mediante su
} 


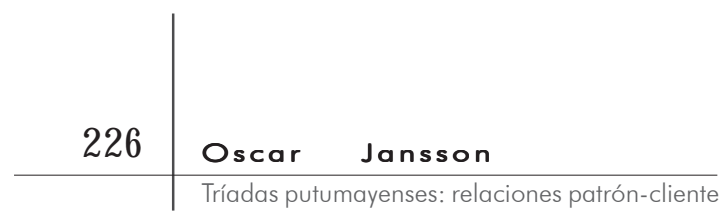

calefacción en una cuchara sobre fuego y su disolución, con una gota de ácido sulfúrico disuelto en agua y tres de permanganato de potasio, debe producir un líquido claro y transparente. Si la mercancía ha sido mezclada con pastillas de aspirina molidas o cera de velas rayada, el líquido sale embarrado y gris. La siguiente fase del ensayo, en la que el comisionista echa el líquido sobre su muñeca, establece, según los comisionistas, la proporción de mugre en la mercancía desde la elaboración de las hojas en la finca del cultivador. Al secar, la mercancía de buena calidad permanece blanca, mientras una alta proporción de mugre adquiere una textura pegajosa de color marrón, conocida como goma. Cuando se calcula y entrega el pago correspondiente a la cantidad y la calidad de la mercancía, el campesino se va de la casa del comisionista, por lo general para hacer las compras necesarias, y ahora posibles, antes de volver a su vereda. Este intercambio económico, simple en apariencia, está acompañado por un intercambio de favores que sólo muy pocas veces ocurre en conexión directa con la venta de la mercancía. En tiempos económicamente difíciles, el comisionista concede pagos adelantados por mercancía cuya materia prima todavía queda para cosechar, aun cuando con frecuencia ocurre también que otorga préstamos para gastos específicos de los campesinos, que surgen en el contexto de una boda, un bautizo o una inversión particular. Al respecto, Julián dice de su comisionista, "A don Daniel uno va siempre cuando necesita plata, y recibe allí de una. Es muy buena gente".

Es raro encontrar un campesino que no muestre estima por su comisionista. Las expresiones de aprecio por el intermediario, de quien el cultivador recibe la mayor parte de los medios que requiere para las inversiones necesarias para su producción continuada y para solucionar sus problemas personales y familiares, igual que su dependencia del mercado, tienden a mostrarse mediante el énfasis en la generosidad del comisionista y su cualidad de "hombre muy humano". Nombres como don Daniel, don Esteban y don William suenan como autoridad protectora, con fides, tal como ha sido definida por Benveniste (1969. 117) la confianza que los mortales ponen en los dioses y de esta manera se aseguran de una garantía de asistencia divina en tiempos de angustia y pavor. Como señala Wolf (1966a: 81), estas relaciones de lealtad y confianza implican las sanciones sociales que las rigen, que suponen, a su vez, la existencia de símbolos 


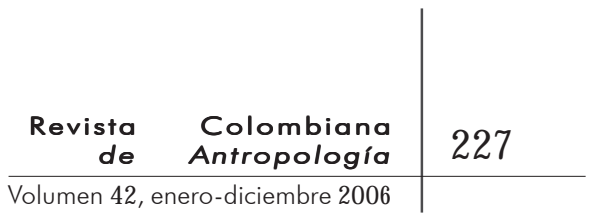

que fortalecen y representan las otras relaciones. Las expresiones continuas de estima hacia el comisionista preservan su credibilidad y su buena fama como comprador fiable y benefactor de sus campesinos, lo que contribuye, obviamente, a reducir tensiones potenciales entre el vendedor y el comprador de materia prima, obliga al campesino a aceptar los precios establecidos por el comisionista y subraya de manera implícita que toda tentativa de diluir la mercancía equivale a un acto de ingratitud.

Un símbolo que representa y fortalece a su vez la relación de simple intercambio económico entre el comisionista y el campesino es el cubo de base. Los comisionistas prefieren recibir la mercancía cortada en dados, prueba de que no ha sido diluida. Para los cultivadores, el hecho de presentar su producto en cubos significa el aumento relativo de la ganancia, en vista de que los cubos contienen una porción más alta de líquido que la mercancía suelta y, por tanto, pesan más que una misma cantidad en polvo. De esta forma, la lealtad del campesino se manifiesta concretamente en un acto mediante el cual el comisionista obtiene mercancía de alta calidad pero por un precio desproporcionadamente alto, intercambio que es difícil calificar en otros términos que como muestra tangible e intangible de la buena voluntad que acompaña la simple transacción.

Sin embargo, el endeudamiento moral del vendedor supone una lealtad más allá de lo simbólico, e incluye la obligación de no cambiar de intermediario en ninguna circunstancia. En vista de la caída del precio de la base de coca y de las ganancias relativas, que podrían llevar al campesino a buscar mejores ofertas, esta obligación tiene una función clave para el mantenimiento del flujo de dinero del que vive el comisionista. Los comisionistas compiten entre sí, pero la entidad compradora que más amenaza sus posibilidades de obtener la mercancía de sus clientes son las Farc (Fuerzas Armadas Revolucionarias de Colombia), que ofrecen un precio mucho mejor que ellos. Para mantener la lealtad de sus clientes frente a este competidor, los comisionistas cuentan no sólo con el endeudamiento moral de sus clientes; también, con el gran apoyo que les ofrecen los paramilitares de la región, quienes, desde la entrada de las AUC (Autodefensas Unidas de Colombia) al bajo Putumayo, sancionan con la pena capital la venta de mercancía a las Farc. Mientras ninguno de los cultivadores entrevistados sabe explicar cómo es que las autodefensas se enteran siempre de la transacción entre un campesino y los representantes 


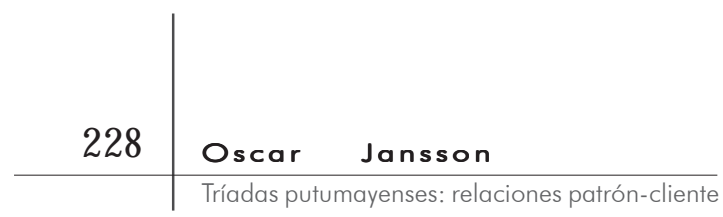

de la guerrilla -todas las ocasiones en una zona bajo fuerte control de esta- existe consenso sobre el riesgo mortal que se corre: quien resida en una zona paramilitar y le venda a la guerrilla pronto tendrá su nombre en la infame lista negra de las AUC. Según un cultivador de coca de una vereda en el Valle del Guamuéz: "Se enteran siempre, porque se enteran de todo, y entonces le matan a uno, pero de una. Aquí han matado harta gente”.

\section{ÉtTica Y GÉNESIS DEL PATRONAZGO}

Y EL CLIENTELISMO

N LA BÚSQUEDA DE LA GÉNESIS DE LA RELACIÓN PATRÓN-CLIENTE, LOS - estudios históricos, al igual que las etnografías de sociedades L campesinas contemporáneas, se concentran en el proceso de socialización entre partes asimétricas. Mientras exista una dinámica distinta en sociedades complejas en la que el surgimiento de la relación se conceptualiza mejor como un proceso de estratificación entre socios inicialmente simétricos (Wolf, 1966b), los casos de cultivadores de coca que mediante grandes esfuerzos y ambiciones emprendedoras se establecen como comisionistas, y en este papel logran utilizar una red de relaciones de amistad y parentesco ya existente para la formación de su grupo de clientes, representan una absoluta minoría. Por eso, la génesis de la relación entre el campesino y el comisionista se debe concebir en términos de una coalición asimétrica que pasa del entrelazamiento simple al múltiple, proceso que, según Wolf (1966a: 83), se inicia con el intercambio informal de favores mutuos con el fin de suavizar la interacción económica, y termina convirtiendo la coalición entre la parte superior y el grupo de inferiores en una serie de coaliciones diádicas. Sin embargo, esta fórmula se basa en el ejemplo de la transformación sucesiva de una relación entre el capataz y los obreros en una plantación, y no refleja, por tanto, la transformación correspondiente de la coalición entre el campesino y el comisionista. Dado que la transacción simple entre ellos constituye un riesgo para ambas partes y por eso es conveniente efectuarla en presencia de pocas personas, el patrón nunca se encuentra con sus clientes como grupo, excepto en su contabilidad. Esto significa que la personalización de la coalición entre el comisionista y el campesino 


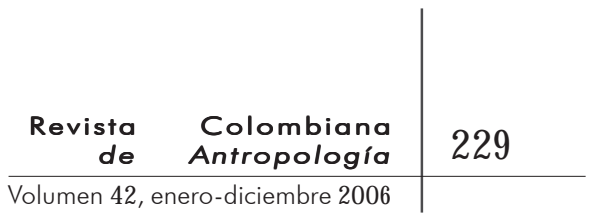

cuenta con condiciones más favorables incluso que la personalización de la coalición entre los obreros y el capataz en el ejemplo de Wolf, porque entre el comisionista y el campesino existe, desde la primera transacción, una coalición diádica en la que el campesino es reconocido como individuo y no sólo como miembro de un colectivo.

La personalización de la coalición se facilita también por el intercambio de información personal que, al igual que las reuniones individuales entre las partes, se genera por la naturaleza del negocio. Como el comisionista necesita saber las fechas y las cantidades previstas para entregas futuras de la mercancía elaborada por el campesino, es conveniente que conozca también si hay cambios referentes a la variedad de coca que cultiva, si en la familia hay enfermedades o situaciones que complican el trabajo agrícola, si faltan medios para comprar los insumos necesarios para elaborar la base o existe algún problema con los cultivos, por ejemplo, pérdida de cosechas por fumigación aérea. Mientras ni comisionistas ni campesinos suelen acordarse del inicio de su intercambio de favores, es probable que las muestras tangibles de buena voluntad por parte del comisionista aparezcan en el contexto de varios relatos de los campesinos sobre sus necesidades personales y diversos asuntos íntimos.

Si se considera que la asimetría es una condición fundamental de la relación entre los cultivadores y los comisionistas, se sigue que su situación de clase ubica fácilmente el estudio de sus demás particularidades en un paradigma de economía política, no necesariamente en términos de la supervivencia de relaciones feudales -aun cuando se ha observado la persistencia de categorías recíprocas de maître y fidèle (Major, 1992)-, sino también como una institución cuyo surgimiento y mantenimiento en diversos contextos se ve favorecida por la dependencia capitalista (Rothstein, 1979. 32f). Sin embargo, existe consenso en que las muestras de buena voluntad intrínsecas a la relación, y sus implicaciones para manifestaciones de honor y vergüenza (Hobbs, 1997), representan su componente más interesante. Sobre la génesis de la ética del patronazgo y el clientelismo en el mundo mediterráneo antiguo, Saller (1982: 10-16) presenta la hipótesis de la lealtad obligada del cliente como consecuencia de la imposibilidad de la evaluación precisa y el reembolso exacto en el contexto de favores diarios, que puso al cliente en una situación de endeudamiento prolongado con su benefactor, que 


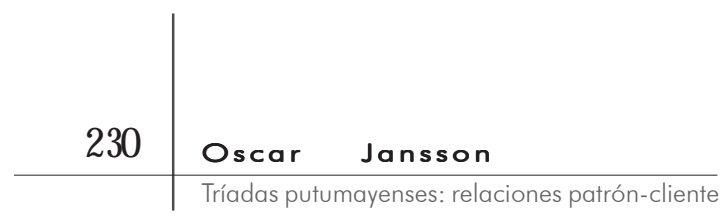

sólo podía aliviar mediante su exposición pública. Observaciones de la práctica del dar y el recibir beneficios como constituyente del principal lazo integrante en la sociedad mediterránea antigua -cómo la de Séneca en De Benef- han permitido sugerir también que los principios éticos del patronazgo y el clientelismo desempeñaron un papel clave para la integración y la cohesión de la sociedad (Crossan, 1991: 65), y para el surgimiento de la gratitud y la ingratitud como virtudes y pecados sociales y políticos, respectivamente (Danker, 1982: 430). Eisenstadt y Roniger (1980: 2) sugirieron conceptuar la relación como un modelo para estructurar el intercambio social en el cual las muestras de buena voluntad se podrían interpretar como manifestaciones de reciprocidad generalizada necesaria para establecer lo que Durkheim (1997) denominaba elementos precontractuales de la vida social, y de esta forma crear una base de seguridad frente a los riesgos e incertidumbres implicados en el intercambio económico.

Esta interpretación de la relación parece coherente con la observación frecuente de su manifestación en escenas fuera o al margen de la ley, en las que la protección jurídica de las partes es inexistente o muy débil. No obstante, hay razones para cuestionar la veracidad de la suposición del carácter intrínsecamente beneficioso de la relación para el cliente. Lo que parece una respuesta funcional a la desigualdad y a la hostilidad puede concebirse también como el enmascaramiento de la dominación y la subordinación económica como autoridad protectora e infantilización. El análisis en estos términos se motiva no sólo por el hecho de que la función mediadora que supuestamente cumplen las muestras de buena voluntad por parte del patrón no concierne la relación asimétrica como tal, sino más bien sus efectos, y también porque las muestras de buena voluntad perpetúan la asimetría al limitar las posibilidades que tiene el cliente de desarrollar nuevas formas de adaptación al mercado en que opera.

\section{La estructura triádica detrás la díada}

〔 I A LOS EFECTOS DESCRITOS DE LA RELACIÓN SE AÑADE EL HECHO DE $\checkmark$ que el patronazgo como tal requiere de la presencia continua de la presión económica y existencial que el patrón pretende aliviar, se ve que la relación únicamente se puede concebir como 


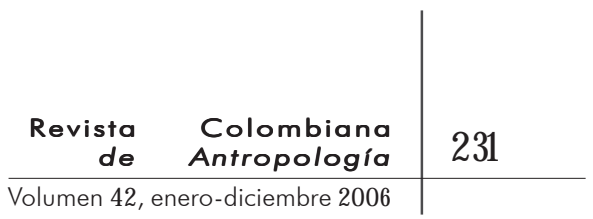

diádica si esa presión sólo la ejerce el patrón, en cuyo caso, y como se ha sostenido en el pasado, la relación se asemejaría, sobre todo, a un simple ejemplo de extorsión (Slater, 1973).

Mientras el comisionista contribuye, a su manera, a la inseguridad de sus clientes, los cultivadores de coca están sometidos a presión por diversas entidades políticas. La coalición se fortalece en gran medida por la fumigación aérea, que mediante la destrucción de cosechas hace crecer la dependencia que tienen los campesinos de su comisionista, sin beneficiar económicamente a este a corto plazo. Lo mismo puede decirse de la erradicación manual de plantas de coca efectuada por unidades de la policía o el ejército, y del control de la venta de gasolina y de otros insumos necesarios para la elaboración de la base. Tampoco se debe subestimar el papel que desempeña - para el mantenimiento de las coaliciones entre los campesinos y sus comisionistas- el terror que causan los asesinatos cometidos por unidades paramilitares de los campesinos que venden su mercancía a las Farc o que parecen apoyar a ese grupo de otra forma.

Con la misma hermenéutica de sospecha que permite pensar la relación patrón-cliente como un enmascaramiento, es posible suponer que la ética del clientelismo es una buena oportunidad para pensar el cumplimiento con la prohibición paramilitar de aceptar las ofertas ventajosas de las Farc como el mantenimiento voluntario de lealtad moralmente correcta hacia un benefactor, en vez de una estrategia para manejar una amenaza constante contra la vida. Sin embargo, mediante la apropiación del valor agregado de su producto, al campesino se le mantiene sistemáticamente en una situación de escasez de medios: así, en 2006, el precio que se le ofrecía por gramo de base equivalía a menos de la mitad del de 1998. En el precio constante de venta al por mayor en Estados Unidos, esta caída se refleja como el aumento sucesivo de la proporción de trabajo no pagado del productor de materia prima, para beneficio de quienes se apropian del valor agregado de la cocaína que proviene de esta región. En relación con esas entidades e individuos, el comisionista representa sólo un canal para la extracción de valor agregado, y su parte en la explotación del campesino se limita a una comisión comparativamente modesta.

Como el patrón se aprovecha de temores e inseguridades de su cliente, que no sólo originan en él, Stein (1984) propuso clasificar la relación como una tríada, cuya tercera parte es la misma jerarquía de poder cuyas implicaciones para el cliente pretende 


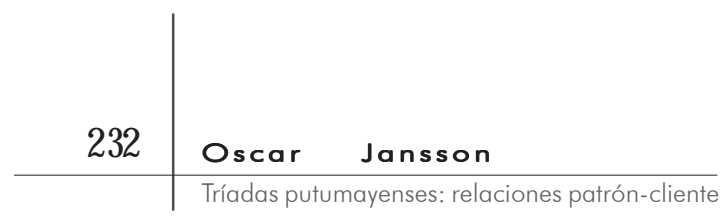

mediar el patrón. Esta fórmula se basa, sin embargo, en la idea kafkiana de una sola burocracia a la que el ciudadano se encuentra sometido incondicionalmente, sin posibilidad de participación, y frente a la cual el patrón aparece como mediador en el espacio entre la muralla China y el emperador inaccesible (Ibid.: 31. En vista del conjunto de condiciones frente a las que el cultivador de coca acepta y agradece la ayuda condicional de su comisionista, la imagen triádica de la relación patrón-cliente se vuelve útil sólo si limitamos el concepto de jerarquía de Stein para comprender la estructura de poder apropiador en la cadena de producción de cocaína. En esta tríada, obviamente, el comisionista no solo está al servicio de su cliente, sino también de intereses superiores, que por definición están en conflicto con los del campesino.

\section{La doble identidad del comisionista}

F STA CONSISTE EN SER, A LA VEZ, SUPERIOR E INFERIOR, PATRÓN Y CLIEN$\sqcup$ te, y-quizá el aspecto moralmente más contradictorio de su cara de Jano, como se verá más adelante- benefactor y traidor. Los comisionistas activos en el bajo Putumayo han trabajado para diferentes dueños en distintos periodos, casi siempre sin saber la identidad de su verdadero patrón. Entidades colectivas como los carteles de Medellín, de Cali, del norte del Valle, las AUC y, últimamente, los llamados Rastrojos -grupo paramilitar constituido por ex miembros de las AUC que asumió sus funciones en el negocio de la coca poco después de la desmovilización formal de ese grupo en marzo 2006- figuran con frecuencia en los cuentos de los compradores de materia prima; pero de los individuos responsables dentro de aquellas formaciones sólo se conocen los enlaces inmediatos con quienes los comisionistas entran en contacto personal. Estos enlaces incluyen al personal de "la bodega" -lugar de tránsito en donde se almacena la mercancía conseguida por el comisionista, antes de ser vendida y sometida a una nueva prueba de calidad, conocida ahora como la rectificación, para determinar la comisión que le corresponde- y al patrón duro, dueño o administrador de la bodega igual que el Chongo, laboratorio donde la mercancía se oxida y cristaliza después. 


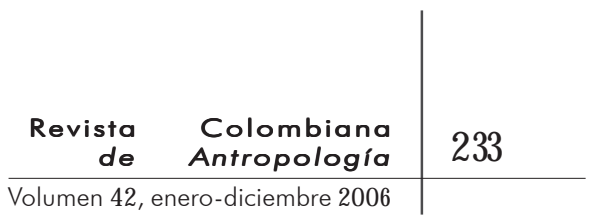

La relación entre el comisionista y el patrón duro, bien sea este un hombre de negocios independiente, el administrador nombrado por un cartel o el comandante local de un grupo paramilitar, es de entrelazamiento múltiple, parecido formalmente a los dobles lazos entre el comisionista y el campesino. En la mayoría de los casos, el negocio supone que el comisionista reciba créditos de su patrón, ya que por lo general carece de medios para pagar al productor de materia prima. Estos pagos adelantados son intrínsecos al funcionamiento del negocio y, por tanto, no constituyen necesariamente una muestra de buena voluntad. Sin embargo, es normal que los comisionistas perciban los créditos como una muestra de confianza, lo que crea un sentimiento de obligación y deuda moral frente a su patrón. Así, se crea la lealtad necesaria que el manejo del dinero del patrón requiere del comisionista. De cierto modo, la lealtad puede interpretarse como una estrategia de supervivencia, ya que el hecho de volarse con el dinero se castiga siempre con la muerte, pero la lealtad supone el cumplimiento con normas más allá del simple respeto por la propiedad del patrón, por lo que el comisionista puede cualificar para ayudas adicionales del patrón en diferentes casos de emergencia. Un comisionista apreciado que cae, es decir, a quien la policía detiene y pierde la mercancía y el dinero en su poder, puede contar con el apoyo de su patrón para el proceso judicial. Si se determina que la responsabilidad por el hecho de caer no es del comisionista, un juicio que según comisionistas depende de la buena voluntad del patrón, tampoco queda debiendo la mercancía o el dinero que pierda. Mientras cumpla con las normas del negocio, el comisionista va acumulando también una especie de credibilidad, que puede servir para salvarle de sanciones del patrón duro en caso de que algún día rompa con las normas. Esto se refleja particularmente en las diferentes sanciones que tiene la falta de cumplir con una de las normas más fundamentales del negocio, la utilización de un sistema de clasificación de la mercancía según su calidad. Se supone que el comisionista debe mantener separadas las diferentes clases de mercancía que obtiene de los campesinos, y que no intentará mezclarlas con el fin de hacer pasar por mercancía de alta calidad una cantidad aumentada ilegalmente. Si el comisionista que entrega mercancía mezclada lleva tiempo demostrando lealtad puede escaparse con un plazo para entregar el dinero que debe, pero si ha habido problemas anteriores 


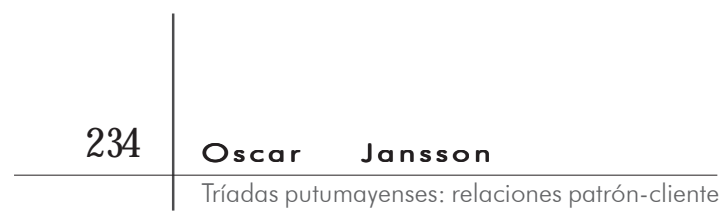

de otro tipos el plazo estará acompañado de una amenaza a su vida. Para quien vuelva a entregar mercancía de mala calidad, el castigo es, por lo general, la muerte.

Dado que el papel de intermediación que desempeña el comisionista en la tríada implica la mediación entre una entidad que desea sacar un máximo de valor agregado y otra que necesita quedarse con la más alta proporción posible, y cobrar una comisión lo más grande para sí mismo, su función se describe de forma más adecuada como la de un corredor. Boissevain (1974: 148) distingue un corredor de un patrón mediante la referencia al acceso a recursos de primer orden -tierra, puestos de trabajo, etcétera- y de segundo orden: contactos estratégicos. Mientras el patrón dispensa el primero, el corredor dispensa el último o, dicho de otra forma, el corredor hace posible el acceso a patrones. En tanto el comisionista maneja capital económico y proporciona medios para sus clientes, el capital en cuestión no es suyo sino de su patrón, lo cual quiere decir, como observó Wolf (1967: 231), que su poder no es original sino derivativo. Como corredor, el comisionista está a merced de su patrón, una relación que, como se verá, se vuelve muy visible cuando la autoridad a la que responde está representada por grupos paramilitares. La consecuencia es que el comisionista difícilmente puede negociar con su patrón, y que, por tanto, debe actuar en favor de su patrón a su propia expensa si hay conflictos, para compensar luego soluciones desventajosas para sí mismo a expensas del campesino. Por eso, caídas en la producción como las causadas por la fumigación aérea no afectan el precio de venta del producto final, ya que esto reduciría las ventajas comparativas del patrón y, por tanto, su cuota de mercado: se compensan siempre mediante la reducción del precio que se ofrece al campesino por la materia prima.

Por último, es importante destacar que el comisionista no es solo un corredor de flujos de capital, sino también de información. Es el Hermes de su patrón duro, por medio de quien el campesino obtiene, sobre todo, falsas noticias y explicaciones de acontecimientos recientes y coyunturas actuales. Por ejemplo, la reducción de la compensación por gramo para el campesino nunca se explica en términos de la ambición de acumular capital de los comisionistas o de sus patrones, sino con una variedad de mentiras entre las cuales unas, como se verá más adelante, se encuentran al borde de lo alucinante. 


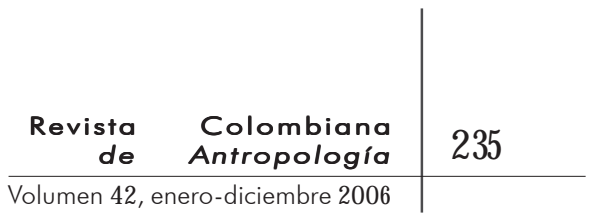

\section{La tríada bajo las autodefensas}

ESDE SU ENTRADA EN LA REGIÓN EN 1998, LAS AUTODEFENSAS, Y POSTEriormente los llamados Rastrojos, han estado aliados con los comisionistas en el bajo Putumayo, alianza que desde la perspectiva de los últimos puede entenderse ventajosamente como una concesión necesaria de libertades políticas que se intercambia por la protección militar de sus intereses económicos, muy similar a la relación identificada por Marx entre "burgueses particulares" y el nuevo régimen autoritario en El dieciocho Brumario de Luis Bonaparte (2003). Después de casi dos décadas de cobro de impuestos a los comisionistas, a los patrones duros y a los transportadores de carga de los traficantes que compraban cocaína de los patrones duros, a finales de la década de 1990 las Farc comenzaron a sacar a los comisionistas del negocio para reemplazarlos ellos mismos, regulación forzosa que les permitió obtener mayores ganancias al completar su cobro de impuestos con el de comisiones. Si las Farc en algún momento habían hecho favores a los carteles o habían brindado alguna clase de apoyo para el funcionamiento de la cadena de producción de cocaína, de ese momento en adelante se convirtieron en sus antagonistas. Frente a la amenaza directa de las Farc contra su negocio, los comisionistas encontraron un aliado importante en el frente Sur del Putumayo del bloque Central Bolívar de las AUC. Como es bien sabido hoy, las masacres de las autodefensas entre 1999 y 2000, al igual que sus asesinatos selectivos posteriores contra miembros de las milicias de la guerrilla y sus supuestos auxiliadores, resultaron ser, como en toda la historia del empleo de escuadrones de la muerte contra elementos subversivos, una estrategia eficaz para reducir la influencia de la guerrilla en la región.

Sin embargo, para mantener el poder social y económico, la libertad política de los comisionistas y de los "burgueses particulares" -en el ejemplo de Marx- debía reducirse considerablemente (Ibid.: 93). La presencia de las autodefensas permitió a los comisionistas continuar explotando a sus clientes, pero con la condición de que ellos mismos cayeran también bajo un control muy fuerte. De esta forma, si seguimos aplicando el lenguaje de Marx, para los comisionistas el establecimiento del control paramilitar en el bajo Putumayo significaba el disfrute de la protección de una espada de Damocles, que además de protegerlos 


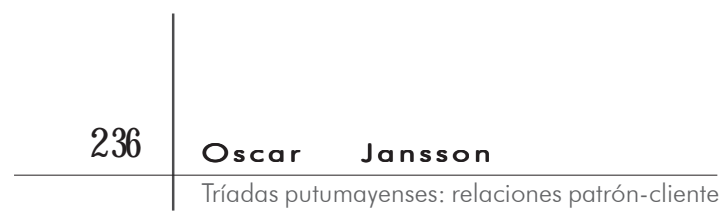

colgaba sobre sus cabezas. Al principio, esta pérdida de libertad se expresó sólo mediante el sometimiento a la autoridad tributaria de las autodefensas, que exigían de los comisionistas un impuesto por cada kilo comprado. Mientras ese costo adicional se podía compensar bajando el precio ofrecido a los campesinos, hubo comisionistas que sufrieron pérdidas menos reparables, relacionadas con la protección paramilitar En 2003 don Ramón, comisionista en La Hormiga, recibió la visita de miembros de la escuadra urbana en el pueblo, que le acusaron de no haber pagado el impuesto correspondiente a los kilos que movía. Lo llevaron a una finca donde lo mantuvieron encerrado durante una semana antes de soltarlo, pero confiscándole las veinte millones de pesos y quince kilos de mercancía que tenía en su poder a la hora del secuestro.

Es posible discernir también otra alianza, equivalente a la alianza entre el frente Sur del Putumayo y los comisionistas en el terreno, entre las AUC y el cartel que controlaba la exportación de la cocaína producida en la región a la hora de la entrada paramilitar, que los comisionistas en la región señalaban como el cartel del norte del Valle. Los impuestos que cobraban las Farc constituían una presión predatoria sobre el narcotráfico como empresa productiva, ya que aumentaban considerablemente el costo de producción de un producto cuyo mercado es demasiado competitivo para permitir que semejantes incrementos se compensen mediante el incremento del precio del producto final. Si al costo de esta predación de las Farc se añade el aumento que representaba su cobro de comisiones una vez establecidos como intermediarios, la perspectiva del cartel que intentaba sacar un máximo de valor agregado del tráfico de cocaína tiene que haber sido una desde la cual se reconociera la necesidad de medidas inmediatas para bajar el costo de producción, sobre todo en el contexto de la caída de la producción total prevista por las fumigaciones.

Mientras que el establecimiento del control paramilitar en zonas claves para el narcotráfico, dominadas antes por las Farc, permitió al cartel ahorrar sumas considerables a partir de 1999, los acontecimientos posteriores sugieren, sin embargo, que las autodefensas avanzaron en sus propios intereses sucesivamente, a expensas de los de cualquier cartel. De cobradores de impuestos se convirtieron en productoras de hidroclóridro de cocaína, comprando la base a los comisionistas y refinándola en 


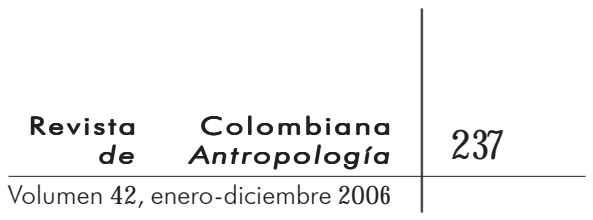

laboratorios bajo su control en el Valle del Guamuéz. En un contexto de escasez cada vez más notable de materia prima debido a la fumigación aérea, es probable que el cartel considerara esa competencia como muy hostil. El acontecimiento que marcó el cambio definitivo de lealtades por parte de las autodefensas en el bajo Putumayo sucedió en diciembre 2004, cuando una unidad paramilitar interceptó un carro que transportaba dinero del cartel, destinado a sus comisionistas, y robó su contenido. Ya que ese dinero nunca llegó a los comisionistas, el precio cayó rápidamente de 1700 pesos por gramo hasta 1500 , caída que según muchos campesinos fue explicada por sus comisionistas como una consecuencia de la ruptura en el flujo de dinero, causada a su vez por una pausa colectiva en el consumo de cocaína entre los consumidores estadounidenses. Sin duda, una mentira alucinante.

Más adelante, en 2005 cuando las autodefensas se habían establecido como los únicos "patrones duros" que refinaban base y sacaban cocaína de la zona bajo su control, la espada de Damocles cayó con todo su peso sobre los comisionistas que operaban en cercanías al mando central paramilitar en El Placer. Allí, las autodefensas decidieron, en un esfuerzo por maximizar la extracción de valor agregado durante el poco tiempo que les quedaba para la desmovilización prevista en 2006, sacar a los comisionistas del negocio. Así, no sólo se ahorró la comisión hasta entonces cobrada por los últimos: se crearon también condiciones ventajosas para sacar un máximo del valor agregado producido por el campesino. Refinando al mismo tiempo que comprando directamente materia prima, el frente Sur del Putumayo ofrecía, entre noviembre 2005y su desmovilización en marzo 2006, la menor compensación por gramo de base conocida en la historia del cultivo comercial de coca en la región: 900 pesos. Mientras tanto, la guerrilla ofrecía 1900. Dice Emilia, de una vereda cerca de El Placer, "Sabíamos que la guerrilla pagaba más del doble, pero como los paracos mataban a quien no les vendiera a ellos nos tocó vender muy barato. La ganancia casi no era nada”.

Por muy eficiente que fuera el patronazgo que ejercían directamente las autodefensas sobre los campesinos, en su esencia similar a una relación extorsiva, fue muy limitado, tanto en el tiempo como en el espacio. La forma más pronunciada del patronazgo de las autodefensas, y por eso la pauta característica en las zonas bajo control paramilitar durante el periodo entre la entrada y la desmovilización, consistía en el tratamiento de los 


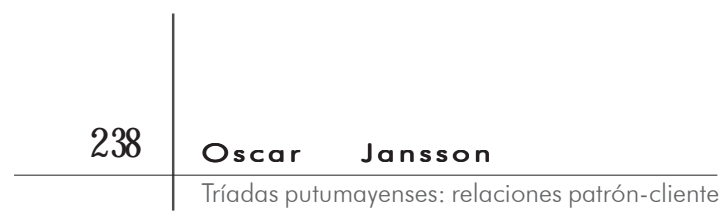

comisionistas como clientes y corredores, para explotar y controlar indirectamente a los productores de materia prima. En esta tríada, la relación patrón-cliente entre las autodefensas y los comisionistas correspondía formalmente al entrelazamiento múltiple típico de la coalición, incluyendo el intercambio de favores tangibles de las autodefensas por favores intangibles de los comisionistas, al lado del simple intercambio económico. Mientras es obvio que el intercambio económico entre los comisionistas y las autodefensas regulaba el precio de compra del comisionista y constituía el fundamento de su capacidad para otorgar ayudas económicas a sus clientes, la verdad es que las relaciones sociales paralelas a lo económico contienen la solución de un misterio aún más delicado. Este misterio concierne a la capacidad impresionante de las autodefensas, igual que de sus sucesores paramilitares -los llamados Rastrojos- de detectar la violación de la prohibición de venta de mercancía a la guerrilla por parte de campesinos individuales. La solución del misterio ilumina el último componente de la doble identidad del comisionista, su papel de traidor. La lealtad obligada del corredor frente a su patrón supone que el comisionista revele información acerca de sus clientes. Cuando un campesino no aparece en la casa de su comisionista con su mercancía el día previsto, el comisionista debe informar a su "patrón duro" paramilitar -sea este las autodefensas o de los Rastrojos- para que el nombre del campesino en cuestión se añada a la infame lista negra. Mientras la lista usada por las AUC en el Putumayo se borró con la desmovilización a comienzos de marzo 2006, la posición de patrón de los comisionistas en la región no quedó libre por mucho tiempo. Como ya he señalado, la función que cumplían las autodefensas la asumen ahora los llamados Rastrojos, una gran parte de cuyo pie de fuerza está constituido por combatientes desmovilizados de las autodefensas procedentes de otras regiones. Para concluir este artículo prestaré atención a la coalición recién formada entre este grupo y los comisionistas, ya que revela la continuidad en el negocio de coca en la región. Sin embargo, primero expondré el caso de las Farc en su papel de corredor entre campesinos y patrones duros. 


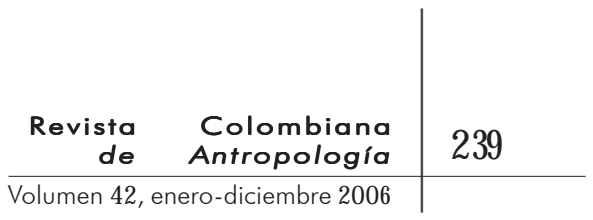

\section{Las Farc, entre patrones duros y campesinos}

I OS CAMPESINOS QUE RESIDEN EN LAS ZONAS CONTROLADAS POR LAS L Farc están obligados a vender su mercancía a la guerrilla. Mientras que los precios ofrecidos por esta son mejores que los pagados por los comisionistas en las zonas bajo control paramilitar, y las Farc disfrutan, por tanto, del apoyo de la mano invisible del mercado en su aspiración a apropiarse del valor agregado que según ellos les corresponde del producto, existe no obstante un mecanismo de control político del comercio. En vista de que las Farc a veces carecen de medios para pagar al cultivador en el momento, mientras este casi siempre requiere compensación inmediata para hacer las inversiones necesarias para su próxima cosecha, se presenta un dilema que se suele tratar mediante la combinación de dos soluciones: una es que el campesino recibe el pago correspondiente a la mitad de la mercancía la primera vez que vende a la guerrilla, mientras la otra mitad se vende fiada para ser pagada en la segunda transacción. De esta forma, la guerrilla queda siempre debiendo la compensación correspondiente a media cosecha del campesino. La otra solución, que se utiliza en periodos de escasez de medios en el frente 48de las Farc, es obligar al campesino a guardar su mercancía en su finca, en una caleta, hasta cuando la guerrilla tenga los medios para comprarla. Debido a la ausencia de dinero para recibir el pago, durante la espera el campesino se vuelve, en la medida que no pueda conseguir ayuda externa, dependiente de la guerrilla para obtener los insumos necesarios para el cultivo continuo de coca y para la elaboración de base, tratándose en la mayoría de los casos de la adquisición de gasolina o de pagos parciales. Mientras se podría suponer que el retraso en los pagos es dañino para la coalición entre el comprador y el vendedor, parece, por el contrario, que la venta de mercancía fiada y el disfrute de ayudas directas de la guerrilla genera la misma imposibilidad de evaluación precisa y reembolso exacto de la cual nace la lealtad obligada del cliente. Esta afirmación podría parecer contradictoria, ya que la guerrilla le debe al campesino y las ayudas recibidas por este responden, en realidad, a necesidades generadas por el retraso de pagos anteriores. Sin embargo, la duración infinita de las transacciones -en el sentido de que una sólo se puede cumplir mediante el acuerdo de una nueva y, por tanto, 


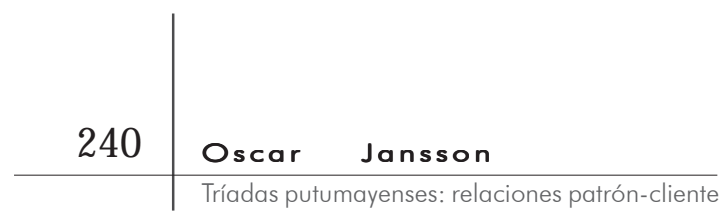

mediante la reproducción del lazo de endeudamiento- crea lazos entre las partes sobre los que un intercambio de favores tangibles por intangibles puede construirse con el tiempo.

Sin embargo, la autoridad protectora correspondiente a la función de un patrón frente a su cliente, que genera la lealtad obligada del campesino frente al guerrilla, se basa en la capacidad que tienen las Farc de mediar con el patrón duro y, de esta forma, establecer precios comparativamente favorables para los productores de materia prima.

A diferencia de los comisionistas, la guerrilla posee no sólo poder derivativo sino también un poder original, basado en su fuerza militar. Mediante una diplomacia basada en la proyección de aquella fuerza, las Farc se vuelven capaces de redistribuir el valor agregado. Igual que los comisionistas, la guerrilla compra la base de los productores de materia prima y la vende a patrones duros, que en el negocio con las Farc se encuentran obligados a pagar no sólo una comisión equivalente a más del doble de la que ofrece al comisionista regular, sino también un impuesto que determina el corredor armado. En consecuencia, el precio de la materia prima obtenido de las Farc durante el periodo en que se hizo la investigación supera, en más de un millón de pesos por kilo, al del mismo tipo de mercancía obtenido de un comisionista regular. Para la guerrilla, los ingresos provenientes de la comisión y del impuesto crean un margen para ofrecer al campesino un precio de compra mucho mejor que el ofrecido por los comisionistas regulares. Obviamente, este sistema de redistribución beneficia no sólo al campesino, sino, ante todo, a la guerrilla. Sin embargo, es fácil identificarla en el papel de protectora de los intereses de los cultivadores de coca frente al poder de los patrones duros, en vista de que su mediación como corredor armado puede interpretarse, de hecho, como una muestra tangible de buena voluntad hacia el campesino -que supera considerablemente las muestras de buena voluntad ofrecidas por los comisionistas- que el campesino a su vez debe compensarse con esfuerzos intangibles.

Mientras las Farc ofrecen mejores precios y por eso disfrutan del apoyo de la mano invisible del mercado para mantener la lealtad de sus clientes, este apoyo debe combinarse con proyecciones de fuerza cuando falla. Por eso, con cierta regularidad pequeñas unidades de la guerrilla piden a los residentes mostrar sus caletas. Las sanciones contra quienes no tengan la mercancía guardada en sus caletas, igual que los que de otra manera se 


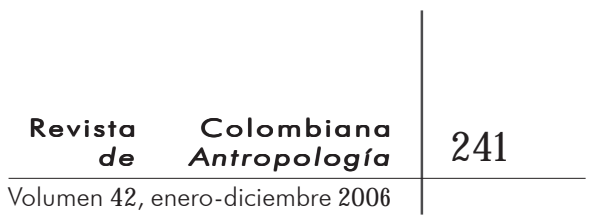

identifican como violadores de la regulación del comercio establecida por la guerrilla, son, en teoría, la muerte y, en la práctica, el desplazamiento forzado. Después de repetidas muestras de falta de cumplimiento con las regulaciones, el campesino recibe una amenaza, acompañada por la orden de irse de la vereda, y la guerrilla manda a otra persona a trabajar a su finca. Sin embargo, se debe destacar que entre los cultivadores de coca en la región existe consenso en que los desplazamientos forzados por la guerrilla como sanciones contra violadores de la regulación comercial son escasos en comparación con el número de asesinatos contra campesinos cometidos por unidades paramilitares en la zona, lo que, sin duda, se debe al precio comparativamente alto ofrecido por la guerrilla.

En la tríada en la cual se sitúan las Farc como corredor, este grupo opera entonces como un parásito sobre el eslabón superior, que a su vez tiene que compensar su pérdida a expensas del superior suyo, es decir, del traficante que compra la cocaína cristalizada al propietario del laboratorio amenazado por la guerrilla. Mientras el aumento del precio del producto no amenace con reducir la ganancia del traficante de forma tal que sólo se pueda compensar mediante el aumento de su precio de venta que reduzca su cuota de mercado, la cadena se encuentra en equilibrio y puede seguir funcionando con relativa seguridad. Cuando el parasitismo de las Farc aumenta el costo de producción de manera que resulta económicamente insostenible para el traficante, este se enfrenta a la necesidad de reducir el control territorial de las Farc que les permite regular el comercio de base en las zonas de cultivo. La reducción de este control territorial es más fácil mediante el despliegue de unidades paramilitares.

\section{La tríada bajo las autodefensas después de la desmovilización}

\footnotetext{
I a entrada de las auc en el Putumayo se conoce sobre todo L COMO una parte del proceso de expansión nacional de las AUC bajo el mando de Carlos Castaño. Sin embargo, la relación entre este último y la organización de traficantes controlada por los hermanos Montoya Henao, parte del cartel del norte del Valle, ya era conocida en 1997 (United States Department of Justice,
} 


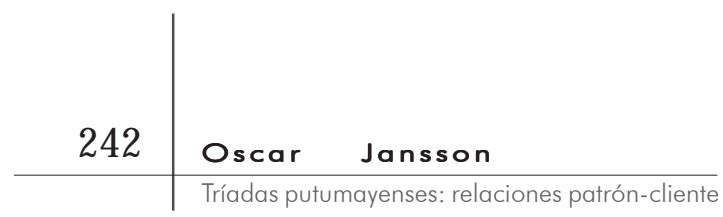

1997: 3). En vista de que el empleo de unidades paramilitares por parte de traficantes de drogas ilícitas -a fin de proteger el negocio y asegurar la extracción de la mayor porción posible del valor agregado creado por los productores de materia primatiene una historia en el Putumayo (Ramírez, 2001 73) al igual que en otras regiones del país donde se cultiva la coca (Gutiérrez, 2005), es probable que un aumento inaceptable en los costos para los traficantes, generado por el parasitismo de las Farc, haya motivado el despliegue de autodefensas en el Putumayo. Independientemente de probables conflictos posteriores entre el frente Sur del Putumayo, es decir, el bloque Central Bolívar del que era parte, y los traficantes que compraban la cocaína putumayense a la hora de la entrada de las autodefensas en la región, surge entonces una pregunta respecto a la desmovilización de las últimas: cuando los aproximadamente quinientos integrantes de este frente paramilitar entregaron sus armas en la vereda de La Esperanza cerca de Puerto Asís el 1de marzo 2006, y el alto comisionado para la paz declaró su desmovilización como un paso significativo para consolidar la paz de la región, ¿qué pasó entonces con la tríada que habían encabezado por tanto tiempo, con éxito? Al parecer, la respuesta se encuentra detrás del nombre, curiosamente metafórico, de los Rastrojos.

Cuando los árboles maderables se tumban crece el rastrojo, y quince días después de la desmovilización del frente Sur del Putumayo su nuevo patrón, con el mismo nombre, llamó a los comisionistas de Puerto Asís, para informarles que seguirían comprando base de sus clientes, bajo la autoridad de este nuevo grupo. Los Rastrojos financiarían su negocio comprando, por un precio reducido, la base que consiguieran los comisionistas; no obstante, mediante la reducción del precio ofrecido al campesino, los comisionistas todavía podrían tener margen para ganar una comisión suficiente. En cambio, exigieron la lealtad absoluta de sus clientes. Los Rastrojos habían copiado la estructura orgánica de las escuadras urbanas de las autodefensas, igual que su modus operandi en el patronazgo de comisionistas y en el proyecto continuado de asesinar a los supuestos auxiliadores de las Farc. Obviamente, tal reemplazo de las autodefensas no hubiera sido posible sin enlaces entre el patrón que dimitía y su sucesor. Antes de comenzar el proceso de reclutamiento local, principalmente entre integrantes desmovilizados del frente Sur del Putumayo, el pie de fuerza de las unidades de los Rastrojos 


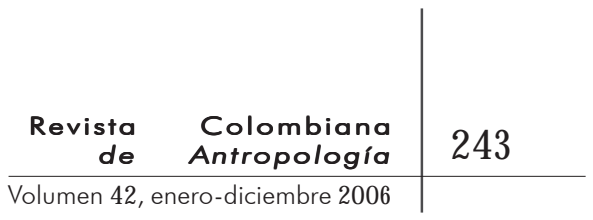

en Puerto Asís, Orito y La Hormiga se constituyó, sobre todo, por desmovilizados de los grupos que antes estaban activos en el Valle del Cauca, lo que permite diversas hipótesis acerca de la continuidad en el negocio de coca bajo su autoridad. Queda por investigar si el proceso de transición entre el dominio de las autodefensas y el de los Rastrojos -que sitúa la desmovilización en un modesto paréntesis entre un patrón y su sucesor- fue planificado en colaboración entre las autodefensas y los narcotraficantes antes de la desmovilización. Por ahora me limito a describir los efectos de la transición vividos por los cultivadores y los comisionistas. Cuando los comisionistas reciben su financiación de los Rastrojos, quienes a su vez están financiados por un traficante residente en Medellín, el precio que ofrecen al campesino es, obviamente, menor que el ofrecido durante la coalición precedente entre los comisionistas y las autodefensas, excepto en la cercanía inmediata de El Placer, donde el precio en la tríada bajo los Rastrojos es, de hecho, superior en comparación con el precio bajo la explotación radicalizada durante los últimos meses de dominio de las autodefensas en el área. Los comisionistas siguen exigiendo la misma lealtad de los campesinos, y mientras la lista negra de las AUC se borró con la desmovilización, los Rastrojos establecieron una nueva.

El principal cambio experimentado por los comisionistas después de la desmovilización y la transición consiste en un mayor énfasis en la importancia de cumplir con una norma tradicional en el negocio. En el contexto de las ganancias obtenidas durante la refinación y la transformación de la base en hidrocloridro, cuando la pérdida de oportunidades de obtener materia prima significa la pérdida de ganancias potenciales para el patrón duro, la mayoría de los comisionistas siempre han escuchado que el representante del último les dice que nunca (deben) devolver dinero y siempre (deben) entregar coca. Durante mucho tiempo, esa instrucción representaba, simplemente, una norma, cuyo cumplimiento permitiría al comisionista mantener una buena imagen ante su patrón pero cuya insatisfacción no generaría sanciones: quien devolviera el dinero y, así, hiciera perder a su patrón una ganancia potencial sólo perdería su comisión. Sin embargo, con la regulación del negocio por parte de los Rastrojos esta norma preferida dejó de ser negociable, ya que se volvió la continuación de otra más fundamental: nunca abandonar la coalición con su patrón para entrar en negocios con otro. El 


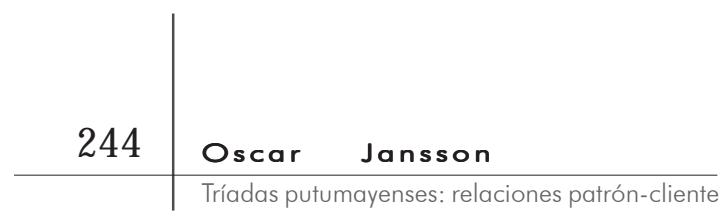

parasitismo de las Farc les permite, dado el precio reducido de base establecido por los Rastrojos, ofrecer por materia prima uno que además de ser mucho más alto que el de compra de los comisionistas, en la actualidad es superior también al precio de venta en la coalición entre estos y los Rastrojos. En vista del incentivo que para los comisionistas significa vender a las Farc, y dado que cada kilo vendido a estas representa una pérdida de dinero para los patrones y, a la vez, el fortalecimiento de su antagonista, devolver dinero en lugar de mercancía se ha vuelto ahora sinónimo del uso ilegal del capital proporcionado por el patrón para comprar materia prima que posteriormente se vende a las Farc. Tal adhesión a principios de economía de mercado se interpreta como enriquecimiento personal a expensas del patrón, por lo que, en la actualidad, el hecho de devolver dinero se castiga con la muerte. El caso más reciente se produjo en abril 2006 en Puerto Asís, cuando integrantes de los llamados Rastrojos mataron a disparos a un comisionista por no entregar mercancía.

\section{Comentarios finales}

AS COALICIONES ENTRE ACTORES SUPERIORES E INFERIORES EN LA CADEna de producción de la cocaína, conceptualizadas como relaciones de entrelazamiento múltiple, es decir, transacciones simples acompañadas por un intercambio continuo de muestras de buena voluntad, permiten interpretar las relaciones de producción desde las dos perspectivas de economía moral y economía política. Por un lado, es posible sugerir que la persistencia en la coalición entre los campesinos y los comisionistas durante las caídas de precios, al igual que la de las coaliciones entre los campesinos y la guerrilla mientras se demoran los pagos, no sólo se debe a las sanciones de los paramilitares o de la guerrilla, sino también a los lazos de endeudamiento moral, percibidos como obligaciones éticas. Por otro, ambas relaciones son susceptibles de las críticas hechas antes contra la suposición del carácter intrínsecamente beneficioso de este tipo de coalición para el cliente; y es imposible negar que la forma de aparición de ambas coaliciones representa el enmascaramiento de relaciones de dominación y subordinación como autoridad protectora e infantilización. 


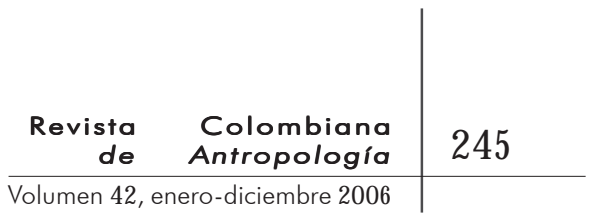

Sin embargo, el intermediario representa, simplemente, un canal para la subordinación de los productores de materia prima, mediante el cual el patrón duro extrae valor agregado. Mientras el intermediario puede sancionar el uso de la violencia contra su cliente, el verdadero poder económico sobre el campesino está en manos del patrón duro y del traficante que compra la cocaína refinada por este. Esto quiere decir que las relaciones patrón-cliente entre campesinos e intermediarios no se pueden entender bien sin tomar en cuenta también la relación entre los intermediarios y sus superiores en la cadena de producción, es decir, las relaciones entre los comisionistas y las autodefensas, reemplazados luego por los llamados Rastrojos, y entre la guerrilla y los llamados patrones duros. En ambas relaciones, los patrones de los campesinos se encuentran en una posición de clientes frente a otros patrones, y, por tanto, como corredores entre dos tríadas separadas.

La distribución del valor agregado creado por los productores de materia prima en las dos tríadas difiere radicalmente en virtud de la capacidad de la guerrilla de practicar su corretaje mediante proyecciones de fuerza hacia arriba. Los comisionistas carecen de esta posibilidad, y no podrían por tanto, aun cuando quisieran hacerlo, mediar a favor del campesino y de sí mismos con la misma eficiencia que la guerrilla. La consecuencia, como se ha visto, es que el patrón puede usar fácilmente al comisionista como un canal y también como un instrumento para una explotación más intensa del productor de materia prima. Además, el comisionista se encuentra -como corredor incapaz de negociar con su patrón mediante la proyección de fuerza- sometido a la autoridad castigadora de su patrón, de la misma forma que el campesino se encuentra a merced de él. Obviamente, los corredores en ambas tríadas sancionan, en su papel de patrones, el uso de la violencia contra sus clientes en casos de violaciones de las regulaciones de comercio. Sin embargo, la necesidad de recurrir al uso de la violencia directa para mantener la coalición depende del funcionamiento de la ética de clientelismo de los campesinos. Aquella ética, cuya expresión es el mantenimiento de lealtad hacia un benefactor, depende a su vez de la capacidad que tenga el corredor de ofrecer muestras tangibles de buena voluntad, es decir, de su capacidad de negociar con su patrón para obtener de este los medios necesarios para ofrecer precios favorables, créditos o préstamos con potencial de endeudar moralmente al cliente. 


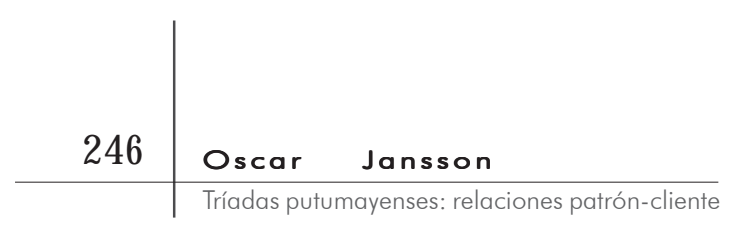

\section{Bibliografía}

Benveniste, Émile. 1969. Le vocabulaire des institutions indoeuropéennes. Volumen I: Économie, parenté, societé. Éditions de Minuit. París.

Boissevain, Jeremy. 1974. Friends of friends. Oxford University Press. Oxford.

Crossan, John Dominic. 1991 The historical Jesus: The life of a Mediterranean Jewish peasant. Harper Collins. San Francsisco.

DANKer, FreDerick W. 1982. Benefactor: An epigraphic study of a GraecoRoman and New Testament semantic field. Clayton Publishing House. St. Louis.

DurKheIM, ÉmILE (1893) 1997. The division of labor in society. Free Press. Nueva York.

Eisenstadt, S. N. y Louis Roniger. 1980. "Patron-client relations as a model for structuring social exchange". Comparative Studies in Society and History. 22 (1).

Gutiérrez, Omar. 2005 Cultivos de uso ilícito en el Meta. Aproximación desde la economía política. PNUD. Bogotá.

Новвs, T. R. 1997. "Reflections on honor, shame and convenant relations". Journal of Biblical Literature. 16 (3).

LeGrand, Catherine C. 1977. "Perspectives for the historical study of rural politics and the Colombian case: An overview". Latin American Research Review. D (D).

Major, Russel J. 1992. "Vertical ties through time". French Historical Studies. 17 (4).

MarX, Karl (1852) 2003 El dieciocho Brumario de Luis Bonaparte. Alianza Editorial. Madrid.

RAmírez, María Clemencia. 2001 Entre el Estado y la guerrilla: identidad y ciudadanía en el movimiento de los campesinos cocaleros del Putumayo. Instituto Colombiano de Antropología e Historia. Bogotá.

Rothstein, Frances. 1979. "The class basis of patron-client relations”. Latin American Perspectives. 6 (2).

SAller, R. P. 1982. Imperial Patronage under the Early Empire. Cambridge University Press. Cambridge

Schmidt, Steffen. 1974. "La Violencia revisited: The clientelist bases of political violence in Colombia". Journal of Latin American Studies. 6 (1).

Slater, Philip. 1973 Earthwalk. Doubleday. Nueva York. 
Stein, Howard F. 1984. "A note on patron-client theory". Ethos. 12 (1).

United States Department of Justice. 1997. "DEA congressional testimony, statement by Deputy Administrator James Milford before the House International Relations Committee Subcommittee on the Western Hemisphere on July 16, 1997'. Consulta 051210:http://www.usdoj.gov/ dea/pubs/cngrtest/ct970716.htm

Wolf, ERIC. 1967. "Peasants and Revolution”. En E. R. Wolf. 2001 Pathways of power: Building an Anthropology of the modern world. University of California Press. Berkeley.

. 1966a. Peasants. Prentice Hall. Englewood Cliffs. NJ.

. 1966b. "Kinship, friendship and patron-client relations in complex societies". En E. R. Wolf. 2001 Pathways of power: Building an Anthropology of the modern world. University of California Press. Berkeley.

Recibido: 2 de octubre de 2006.

Aprobado: $\mathbb{2}$ de noviembre de 2006. 